\title{
"EXORTACIÓN A LA PIEDAD Y MAGNIFICENCIA SEVILLANA", O LA CONTRIBUCIÓN POÉTICA DE ALONSO MARTÍN BRAONES A LA OBRA DE LA COLEGIAL DEL SALVADOR DE SEVILLA (1694)
}

\author{
Nuria Casquete de Prado Sagrera
}

\begin{abstract}
By the end of $17^{\text {th }}$ century, the sevillian Colegial of the Salvador was demolished and again constructed according to the actual building. The difficulties in the development in its construction supposed high costs that had to be financed in any case. And perhaps the most original form of all them is that one here presented, a poetic petition that tries to move the people's hearts and pockets. If we add to this particular situation the character of unique item that seem to have these verses, we find it as an original case among the poor sevillian production of poetical works in the second middle half of the XVIIth century.
\end{abstract}

Aunque el título no puede ser de más actualidad, no se trata de la reforma que estamos viviendo ahora a comienzos del siglo XXI sino de otra, crucial en la historia de la Colegial, que tuvo lugar el último cuarto del siglo XVII. No cabe duda que la Historia se repite a veces ${ }^{1}$.

De aquella obra de hace trescientos años ya se ha escrito, pero un impreso de dos hojas conservado en la Biblioteca Nacional ${ }^{2}$ nos ofrece una curiosa visión: la de un entusiasta sevillano y fervoroso creyente que a través de sus versos intenta incitar a la limosna para sufragar gastos.

Vamos por tanto a acercarnos a esta obrita, no para entrar en valoraciones literarias sino para recrear un momento histórico en los avatares de la Colegial y cómo la vivió nuestro poeta, Alonso Martín Braones.

\section{QUÉ OCURRÍA EN EL SALVADOR A FINALES DEL SIGLO XVII}

La Sevilla de la segunda mitad del Setecientos vivió tiempos difíciles e intensos: pérdida del monopolio con América, crisis económica y demográfica... Parece que sólo en las Artes gozó de un especial esplendor ${ }^{3}$.

\footnotetext{
${ }^{1}$ Este artículo fue editado en el año 2004 en la "Web de la restauración de la Iglesia Colegial del Salvador de Sevilla": <http://www.colegialsalvador.org>, aunque el texto que aquí se presenta ha sido corregido y notablemente aumentado en algún punto.

${ }^{2}$ Biblioteca Nacional, signatura: VE/102/28.

${ }^{3}$ Una síntesis de la historia hispalense de esta época en: A. DOMÍNGUEZ ORTIZ, La Sevilla del siglo XVII, Sevilla, Secretariado de Publicaciones de la Universidad de Sevilla, 1986 (3 ${ }^{\mathrm{a}}$ ed.). También los trabajos de diversos autores en: Sevilla en el siglo XVII: exposición. Sevilla, Ministerio de Cultura, 1983.
} 
Harto difícil debía ser, por tanto, pedir ayuda económica en aquellos momentos, pero eso es lo que pretende precisamente la Colegial, porque en este ambiente el Salvador vive su propia crisis: es necesaria -más bien urgente- abordar una reconstrucción del edificio, entre otros motivos por el estado ruinoso de buena parte de él ${ }^{4}$. La solución definitiva comenzará por la demolición de la Colegial en 1671 y el levantamiento de una nueva fábrica. Pero toda ella se vendrá abajo una madrugada de octubre de 1679 y los canónigos deberán enfrentarse a una reconstrucción y, lógicamente, a nuevos gastos. La recaudación de limosnas va a ser ya una fuente obligada y cotidiana de ingresos.

Prosigue así la obra, ya sin incidentes que debamos mencionar hasta que en 1694 se produce cierto revuelo en la Colegial ante la denuncia que presenta un personaje sobre la calidad de lo construido y la réplica que ello provoca. Pues bien, es precisamente este año y en este contexto cuando entra en escena Alonso Martín Braones, quien escribe una sentida exhortación en doce octavas reales a favor de la construcción de la nueva Colegial.

Aunque no está fechado, el texto no deja lugar a dudas sobre cuándo se escribió y por qué motivo. La tercera octava es así de explícita:

Veinte, y tres años ha que derribado de Nuestro Salvador el Templo vemos; y de ver al Señor à el trasladado dilatada esperanza mantenemos; entretanto el Autor de lo criado en indecente sitio lo atendemos; y da el mirarle allí penas mortales, quando ay piedad, afectos, y caudales.

Si estas estrofas se escriben 23 años después del derribo, que sólo puede ser el de 1671, nos encontramos en 1694. No puede tratarse del hundimiento posterior de 1679 porque estaríamos en 1701 y Alonso M. Braones parece que murió en 1695.

La petición comienza apelando a la generosidad y a la piedad del sevillano moviéndolo a la compasión ante un Dios despojado de su templo. Y lo lleva hasta el extremo de equiparar estas virtudes con el propio ser de Sevilla:

si algo no das al que te dio infinito

dónde está lo piadoso, y sevillano?

Tras éstos y otros semejantes razonamientos, remata en la última estrofa con el argumento que siempre tiene peso para el creyente:

y pues de Dios el premio es bien esperes

en la gloria que eterna te apercibe,

dale tu corta ofrenda al que sin duda

tanto apreció la de la pobre Viuda

\footnotetext{
${ }^{4}$ Sobre todo lo relacionado con la historia y obra de la Colegial ver E. GÓMEZ PIÑOL, La Iglesia Colegial del Salvador. Arte y sociedad en Sevilla (Siglos XIII al XIX), Sevilla, Fundación Farmacéutica Avenzoar, 2000, así como algunos trabajos de F. MENDOZA CASTELLS en la web del Salvador ya citada.
} 
Lo que en síntesis no deja de ser el piadoso "Que Dios se lo pague". Pago que, si seguimos leyendo, ya adelanta al dadivoso Su Ilustrísima con 40 días de indulgencia. Pero antes, no debe faltar un dato muy útil al caso: "La limosna recibe el Canónigo D. Joseph Fernando de León, Diputado de la obra".

Parémonos un poco aquí. Desde el comienzo de la reforma la Colegial venía nombrando un diputado de obra entre sus canónigos. En 1687 fue elegido José Fernando de León y seguía siéndolo en 1694. La relación entre él y Alonso Martín Braones no podemos saber cuándo se inicia, pero no cabe duda que en ese año era estrecha porque ambos salen juntos a pedir limosna y logran recaudar 390 reales de vellón:

en 8 de junio resebi del sr. Don Joseph de León trescientos y nobenta rs. de la demanda que dichos sr. y don Alonso Martín Braones pidieron por las calles en dicho día 5 .

Si bien era frecuente la salida en parejas a pedir limosna, este caso resulta curioso por varios motivos: por no ser canónigo uno de los miembros, por la cantidad recaudada, una cifra respetable teniendo en cuenta que los demás no solían alcanzar en un día los 200 reales y, también, porque sólo salen juntos este día.

A falta de datos ciertos, sólo podemos imaginar que fuera entonces cuando Braones repartió su poemita y por ello la recaudación subió ese día. Aunque visto el éxito no se entiende por qué no repitieron la salida, ¿tan corta fue la tirada? ¿o es que el grueso de la edición tuvo como destino mover los bolsillos de tierras más lejanas? Porque resulta aventurado, aunque no descabellado, hilvanar todo esto con el siguiente apunte:

mas en 7 de agosto resebi del sr. Don Joseph de León mil y quinientos rs vellón que se traxeron de Arcos de la limosna de los papeles que se imprimieron para la obra ${ }^{6}$.

En ayuda de la imaginación para explicar por qué en ningún otro documento se hace mención de este asunto (noticias sobre el proyecto o costes de impresión), tengamos en cuenta que según refiere Ambrosio de la Cuesta -lo veremos más adelante- otras veces el propio Braones sufragaba los gastos de sus publicaciones, por lo que bien pudo hacerlo también ahora. Por otro lado, parece que murió meses después ¿estaría ya enfermo y no fue capaz de continuar esta empresa? ¿pero por qué ni siquiera hay referencias en fechas anteriores? Nada dicen tampoco las actas capitulares, aunque esto es más comprensible porque prácticamente ningún asunto relacionado con la obra aparece en las actas, ya que está completamente delegada en el diputado.

\section{QUIÉN ERA ALONSO MARTIIN BRAONES}

Es necesario ya que nos detengamos en la figura de este personaje hoy desconocido para el gran público pero cuyo rastro podemos seguir a través de otros autores hasta el propio siglo XVII.

\footnotetext{
${ }^{5}$ Archivo General del Arzobispado de Sevilla (A.G.A.S.), Fondo Colegial del Salvador. Fábrica. Libro 574, fol. $6 \mathrm{v}$.

${ }^{6}$ Id., fol. 7
} 
Las obras señeras de dos ilustres sevillanos de esta centuria, Diego Ortiz de Zúñiga y Nicolás Antonio, no recogen dato alguno porque el marco cronológico que ambos abarcan se cierra en fecha muy temprana en relación a la producción de Alonso Martín Braones. El primer autor localizado que nos habla de él es el también sevillano Diego Ignacio de Góngora, quien tal vez conociera a Alonso Martín porque le dedica una larga y elogiosa descripción. La transcribo íntegra porque como se irá viendo fue luego muy copiada por otros autores:

Es natural desta ciudad de Sevilla Dn. Alonso Martín Braones. Estudió la Grammática y las Artes en el Colegio de Sto. Thomás de dicha ciudad, dexó los estudios motibado de conveniencias especiales que le sacaron de los Generales por poner cobro a su hazienda, pero no dejó la afición y aplicación a todas buenas letras, especialmente a la Poesía castellana, que siempre a cultibado con gran primor, y en que a tenido especial Numen, que le conocieron sus Maestros quando le instruían en los primeros rudimentos, y desde cuio tiempo escribía en los certámenes, celebrándose sus obras, no sólo por buenas, sino por dignas de premio, y admirando que en tan corta edad, tubiesen tanto artificio y fondo los conceptos, que reducía a los números y medida de los versos, ajustando los castellanos con las vozes latinas con rigorosa medida y preceptos deste arte. A escrito mucha copia de diferentes poemas a varios asumptos pero los que a sacado a luz asta este año de 1687 que vive son los siguientes, a asumptos sacros y espirituales, porque no solo se recree el entendimiento, con la armonía numerosa de sus elegantes versos, sino que de sus agudos conceptos se excite el alma a buscar lo mejor, sirviendo a Dios y aspire a la perfección; y assí a todo lo que a impreso a puesto por epígraphe y titulo estas palabras A Mayor Gloria de Dios.

Sigue una relación de sus obras ${ }^{7}$. El texto mismo se fecha en "este año de 1687". Como la "Exortación a la piedad..." es posterior, no pudo Góngora lógicamente incluirla en la relación de títulos de Braones y, por extensión, tampoco la recogen los autores que le copiaron.

Aparte este detalle, sí le podemos achacar un par de olvidos: las fechas de nacimiento y muerte de Braones y citar sus otras obras de contenido no religioso.

Lo primero es subsanable a través de varios autores, aunque no hay un acuerdo total para estos datos biográficos tan elementales. Incluso no lo hay con el apellido, que aparece indistintamente como Braones y Brahones, aunque es por la primera forma como aparece el propio autor en sus publicaciones.

Se barajan varias fechas. De su nacimiento dicen A. Riquelme y José de Ceballos en el XVIII que fue el 23 de enero de 1644, fecha que corrobora inicialmente J. Matute, siguiendo a González de León, aunque más adelante afirma sorprendentemente que "En San Esteban, libro III de Bautismos, fol. 168, hay una partida, fechada en sábado 21 de marzo de 1654, de Alonso, hijo legítimo de Alonso González de Briones y de Mariana de Valenzuela", ${ }^{\prime \prime}$ no coinciden ni día ni mes ni año. Lo único que puede explicarse es la

\footnotetext{
${ }^{7}$ D. I. DE GÓNGORA, Varones ilustres en letras naturales desta ciudad de Sevilla. Que pone en este volumen la diligencia de un hijo de esta ciudad deseoso de conserbar la memoria de sus hijos. (S.a.) Manuscrito 59-1-1 de la Biblioteca Capitular y Colombina (B.C.C.).

${ }^{8}$ A. RIQUELME Y QUIROZ, Cenotaphiologium hispanum [1700] (Ms. 58-4-22 de la B.C.C), J. CEVALLOS, Apuntaciones hechas por Dn. Josef de Cevallos desde el año de 1758 hasta 1762 para la Biblioteca española, escritas por él mismo..., s.a. (Ms. 57-2-3 de la B.C.C.), J. MATUTE Y GAVIRIA, Adiciones y correcciones á los
} 
diferencia del día, pero aún así tendría que haber sido a la inversa. Incluso para que se trate de la misma persona hay que admitir como el mismo apellido las formas Braones y Briones, lo que es posible pero muy poco probable. De serlo, justificaría esta intervención del poeta en el Salvador, ya que en la antigua Colegial una de las capillas al parecer más importantes era la de los Briones, aunque en la nueva iglesia desaparece?

En cuanto a su muerte, entre 1685 según Ambrosio de la Cuesta y Saavedra ("Fue de vida ajustada y correspondióle muerte ejemplar lunes 21 de marzo de 1685") y el mismo día y mes pero de 1695 que afirma de nuevo A. Riquelme, es más fiable éste último, simplemente porque las fechas de muchas publicaciones de Braones son posteriores a $1685^{10}$.

El ya citado Ambrosio de la Cuesta -otro autor muy copiado posteriormente y también contemporáneo de Braones- aporta más datos que no recoge Góngora, entre ellos sobre su otra producción literaria. Se resumen a continuación siguiendo el orden del texto original. Dice que fue

docto en toda erudición, empleado en divinas alabanzas y con particular devoción a María Santísima (...) Escrivió varios epigramas latinos, y variedad de versos castellanos en distintos metros con sa[]onados picantes, que de mano andan entre los curiosos, como también muchos sainetes, que en su mozedad dio a las tablas, donde consiguió repetidos aplausos, tales fueron la Mojiganga de $\mathrm{D}^{\mathrm{a}}$ Ynes de Castro con título de -Beber, morir, y vivir = La fiesta de Ynocentes para festejo de Carnestolendas el año de 1665 (...) y otros muchos (religiosos y profanos) que despreciados de su humildad, y desengaño entregó a el fuego". Diversos títulos se publicaron sin su nombre "que dio a la estampa a su costa, repartiéndolos con el cargo de un Páter Noster y una Ave María por las Ánimas Benditas. Escrivió diversas letras en alabanzas del Santísimo, y de María Santísima, Natividad, y Reyes, que se cantaban cada año en las Yglesias, y en particular para que los Niños Seises de la Cathedral cantasen en las Pasquas y octavas.

Pocas noticias se recogen en el XVIII, aunque una de ellas aporta nuevos y curiosos datos:

fue poeta razonable, y su vena era en las cosas piadosas: de buenas costumbres, diestrísimo en la cítara, y gran jugador. Escrivió un papel manuscrito sobre los abusos de los Rosarios en

Hijos de Sevilla ilustres en santidad, letras, armas, artes y dignidad de D. Fermín Arana de Varflora. Sevilla, Oficina Tipográfica de E. Rasco, 1886, pp. 3-5.

${ }^{9}$ Por otro lado, respecto a la antigua colegial, no consta referencia alguna sobre una fundación de los Briones/Braones en el Índice de Capellanías cuyos expedientes se custodian en el Archivo General del Arzobispado, ni sobre lápidas de enterramientos de la familia en la Colegial, por lo que no es posible comprobar esta cuestión del apellido. Esta capilla era de una conocida familia de Carmona, pero en una obra casi coetánea sobre esta villa se habla de los "Briones" no de los "Braones": Fr. J. S. B. Arellano, Antigvedades y excelencias de la villa de Carmona. Y compendio de historias. Sevilla, Simón Faxardo, 1628.

10 A. DE LA CUESTA Y SAAVEDRA, Novisima Scriptorum Hispanorum post Bibliothecam Hispanam cum Appendicibus (1701) (Ms. 59-1-31 de la B.C.C.). (Está en estudio una recopilación de noticias manuscritas de "sevillanos ilustres" conservadas en la Biblioteca Capitular). De nuevo J. Matute remite a González de León para dar como fecha de la muerte el 21 de marzo de 1695. Sin embargo no he logrado localizar en las obras de este autor ninguno de los datos que recoge Matute. 
Sevilla, y sobre que no se devían hacer estaciones con ellos, sino en tiempo de necesidad. Es como un sermón, y es obra manuscrita ${ }^{11}$.

Habrá que esperar hasta mediados de la centuria siguiente para que le dediquen de nuevo atención, aunque en su mayoría recurren a transcribir los textos de Ambrosio de la Cuesta y de Góngora. En nota se recoge una relación de estos autores. En el siglo XX se mantiene la misma tónica, y sólo cabe añadir que José Simón Díaz aporta noticia de tres obritas más de Braones no recogidas en estudios anteriores ${ }^{12}$.

En esta rápida visión a través de los siglos llama la atención el evidente deterioro que va sufriendo la valoración de la obra de Braones. A finales del XVII se celebraban "sus obras, no solo por buenas, sino por dignas de premio" y por "la armonía numerosa de sus elegantes versos" en palabras de Diego Ignacio de Góngora. En el XVIII lo calificará de "insigne poeta" Arana de Varflora, aunque ya Cevallos cambia el adjetivo por el de "razonable". Avanzando en el tiempo, nos puede quedar la duda si Francisco Escudero a fines del XIX incluiría a Braones en su crítica sobre la producción literaria sevillana de la segunda mitad del siglo XVII:

apenas salen de sus prensas más que tratados de teología mística, libros polémicos estériles, y abortos de mal gusto que se había apoderado por completo del fondo y de la forma de nuestra literatura. $^{13}$

${ }^{11}$ J. CEVALLOS, Apuntaciones... Por lo demás, este autor hace una relación de las obras que aparecen en las Glorias de María.

${ }^{12}$ Del siglo XVIII, aparte de los ya citados Riquelme y Cevallos sólo he localizado una referencia, por otra parte escueta y poco original, en F. ARANA DE VARFLORA, Hijos de Sevilla ilustres en santidad, letras, armas, artes o dignidad. Sevilla, Imprenta de Vázquez e Hidalgo, 1791.

Estudios del siglo XIX:

- B. J. GALLARDO, Ensayo de una biblioteca española de libros raros y curiosos II, Madrid, Imprenta y Esterotipia de M. Rivadeneyra, 1866. Se limita a transcribir el texto de Ambrosio de la Cuesta y describe sólo dos obras.

- A. LASSO DE LA VEGA, Historia y juicio crítico de la escuela poética sevillana en los siglos XVI y XVII, Madrid, Imprenta de la viuda e hijos de Galiano, 1871. Copia citando a Gallardo, Cuesta y Góngora.

- J. MATUTE, (1886), ya citado, reutiliza con ligeras variantes y añadidos el texto de Cuesta. También recoge algunos datos de Góngora, Riquelme y Varflora.

- F. ESCUDERO Y PEROSSO, Tipografia hispalense. Anales bibliográficos de la ciudad de Sevilla desde el establecimiento de la imprenta hasta fines del siglo XVIII, Madrid, Establecimiento Tipográfico "Sucesores de Rivadeneyra", 1894. Describe seis títulos.

En el siglo XX:

- M. MÉNDEZ BEJARANO, Diccionario de escritores, maestros y oradores naturales de Sevilla y su actual provincia, 3 Tomos. Sevilla, Tipografía Gironés, 1922. Una vez más son textos extraídos de Góngora y de Cuesta.

- A. PALAU Y DULCET, Manual del Librero Hispanoamericano, Barcelona, Librería Anticuaria de A. Palau, 1949. Describe siete impresos.

- J. SIMÓN DÍAZ, Impresos del siglo XVII, Madrid, C.S.I.C. Instituto "Miguel de Cervantes", 1972, describe cinco obras y en Bibliografia de la Literatura Hispánica VI, Madrid, C.S.I.C. Instituto "Miguel de Cervantes", 1983, otros nueve títulos de Braones de los cuales tres ya aparecen en su trabajo anterior.

${ }^{13}$ F. ESCUDERO Y PEROSSO, F. (ob. cit.) p. 9, recogido también en un interesante trabajo de A. DOMINGUEZ GUZMÁN, "Algunas lecturas curiosas en la Sevilla del siglo XVII", Archivo Hispalense, 205 (1984), pp.77-103. Una breve mención se merece nuestro autor por parte de J. CEJADOR Y FRAUCA, en Historia de la Lengua y Literatura castellana. T. V, Madrid, Tipografía dela "Revista de Archivos, Bibliotecas y Museos", 1916, p. 287, 
Pero lo que no deja margen a interpretaciones es este demoledor juicio:

en la segunda mitad de la centuria (s. XVII) no se editaron nada más que poemas religiosos de pésimo gusto y menos que mediocres logros, como las obras de Pedro Torrado de Guzmán, Francisco de Godoy o Alonso Martín Brahones, que hay que olvidar ${ }^{14}$.

En fin, más vale así, gozar de cierto reconocimiento en vida y que las críticas lleguen tres siglos después.

\section{BREVE COMENTARIO SOBRE LA "EXORTACIÓN A LA PIEDAD Y MAGNIFICENCIA SEVILLANA"}

Aunque carece de datos de impresión, la fecha se deduce de sus propios versos y el lugar no nos cabe duda, pero lo que ya resulta francamente difícil es aventurar quién lo imprimió, ya que las demás obras de A. Martín Braones salieron de los talleres de diversos y conocidos impresores sevillanos: Lucas Martín de Hermosilla, Juan Francisco de Blas, Juan Antonio de Tarazona, etc.

Curioso es sin duda, aunque no extrañe, el carácter de único que parece tener este ejemplar de la Exortación. Tras consultar los catálogos de diversas bibliotecas, locales, nacionales y extranjeras no aparece más referencia que el del conservado en la Biblioteca Nacional de Madrid $^{15}$. Si fue una de esas obritas publicadas por el mismo Braones, no cabe duda de su escasa difusión y su aún más precaria conservación.

Confirma esta exigua pervivencia de la Exortación el constatar que de todos los autores que la mencionan sólo uno de ellos parece haberla visto realmente. Si nos detenemos en la bibliografía que se ha ido citando comprobaremos que en cinco estudios se recoge entre los títulos de Braones, pero de ellos nada menos que cuatro se limitan a citar al quinto, Bartolomé Gallardo, y por tanto el único que debió contemplar un ejemplar, ya que sólo él describe la obra sin remitirnos a otro autor. De los demás, Lasso de la Vega sólo la nombra y los restantes (Escudero, Palau y Simón Díaz) añaden la descripción. ${ }^{16}$

quien se limita a recoger tres de los títulos de Braones, de los cuales los dos primeros son sin duda los más conocidos como iremos viendo: Epitome de los Triunfos de Jesús, Epitome de las Glorias de María y Función de desagravio a la Virgen María. Sin embargo, lo pasan por alto A. DE CASTRO, en Biblioteca de Autores Españoles, desde la formación del lenguaje hasta nuestros días. Poetas líricos de los siglos XVI y XVII (2 tomos), Madrid, M. Rivadeneyra, 1857 y L. F. AGUIRRE DE CÁRCER Y J. I. DÍEZ FERNANDEZ, “Tres escuelas poéticas sevillanas? (Sobre la insistencia histórica e historiográfica)”. Archivo Hispalense 232 (1993), pp. 57-85.

${ }^{14}$ P. M. PIÑERO RAMIREZ, "La literatura sevillana del siglo XVII", Sevilla en el siglo XVII, (1983), pp. 117126.

${ }^{15}$ He consultado los catálogos de bibliotecas de las que se recogen a continuación algunas direcciones de internet. Obviamente no existe la menor pretensión de exhaustividad, tanto por el volumen de bibliotecas consultadas como, sobre todo, porque en muchas de ellas aún buena parte de su fondo antiguo no está accesible por internet: Biblioteca Capitular de Sevilla: <http://www.institucioncolombina.org >, Biblioteca de la Universidad de Sevilla: $<$ http://bib.us.es/ $>$ Real Biblioteca (Madrid): $\leq \mathrm{http}: / /$ www.patrimonionacional.es/realbiblioteca $>$, Library of Congress: 〈http://www.loc.gov $>$, British Library: 〈http://www.bl.uk $>$ y Catálogo Colectivo de Francia: $<$ http://www.ccfr.bnf.fr. $>$ El Catálogo Colectivo de Patrimonio Bibliográfíco Español recoge sólo el ejemplar de la B. N.: $\leq$ http://www.mcu.es/ccpb/ $>$. También he consultado sin resultado la Biblioteca Auxiliar del Archivo Municipal de Sevilla.

${ }^{16}$ En honor a la verdad, la autora de estas líneas tampoco ha visto directamente el original sino la copia microfilmada facilitada por la B.N. 
Tras rastrear la presencia de nuestro autor en algunos inventarios de bibliotecas sevillanas del siglo XVII y principios del XVIII el resultado no puede ser más desalentador. Así, en un estudio dedicado al análisis de treinta bibliotecas particulares sevillanas ${ }^{17}$ sólo aparece una obra de Braones, "Triunfos de Jesús", aunque eso sí, en tres bibliotecas. En otro trabajo sobre cuatro bibliotecas sevillanas del mismo periodo, únicamente se recogen dos obras y ambas en la misma biblioteca y tal vez encuadernadas juntas, ya que aparecen en un mismo asiento con este título: "Triunfos de Jesús y gloria de María"18. Nada parece haber en la importante biblioteca del Conde del Águila, ya de la segunda mitad del XVIII. ${ }^{19}$

De todas formas, la ausencia de noticias no significa, necesariamente, la falta también de ejemplares, ya que las obras de Braones no suelen sobrepasar las cuatro páginas, como esta Exortación, por lo que es muy probable que formen ineludiblemente parte anónima de los numerosos tomos de "Varios" que se recogen en los inventarios, tanto de bibliotecas particulares como de algunas instituciones sevillanas (v.g. San Acasio, Biblioteca Arzobispal, Biblioteca Capitular). Así, los Triunfos de Jesús y las Glorias de María, que son las obras que más se conservan son, a su vez, las de mayor volumen (más de 80 páginas).

También parece merecer un calificativo especial la obrita en sí como estilo literario. Después de rastrear parecidos en casi tres mil títulos de impresos del siglo XVII y parte del XVIII, en su mayoría sevillanos, no he encontrado ninguno que se asemeje a esta Exortación. Aunque sí existieron impresos -y muchos- relacionados con la petición de limosnas, se trata más bien de concesiones reales, indulgencias, noticias sobre recaudaciones para la guerra, etc. A pesar de que sólo han servido los títulos de guía en esta búsqueda, todos ellos inducen a imaginar, por un lado, textos en prosa $\mathrm{y}$, por otro, una literatura jurídica o un estilo puramente informativo que nada tienen que ver con encendidos versos como los nuestros ${ }^{20}$. Lo que no cabe duda es que puede encuadrarse dentro de la tan en boga por entonces producción española de pliegos sueltos o de relaciones de sucesos, entendiendo por tales "textos breves de tema histórico concreto con una intencionalidad de transmisión por medio del proceso editorial"21.

\footnotetext{
${ }^{17}$ C. L. ÁLVAREZ SANTALÓ, "Adoctrinamiento y devoción en las bibliotecas sevillanas del siglo XVIII", La religiosidad popular II. Vida y muerte: la imaginación religiosa, Rubí (Barcelona), Anthropos, 2003, pp. 21-45.

${ }^{18}$ M. J. SANZ y M. T. DABRIO, "Bibliotecas sevillanas del periodo barroco. Datos para su estudio", Archivo Hispalense, 184 (1977), pp. 113-155. Corresponde al inventario de la biblioteca de Domingo de Arbizu.

${ }^{19}$ F. AGUILAR PIÑAL, Una biblioteca dieciochesca: la sevillana del Conde del Águila. Madrid, Cuadernos Bibliográficos vol. 37 (tirada aparte), 1978. Tampoco recoge este autor referencia alguna sobre Braones en su libro La biblioteca de Jovellanos (1778), Madrid, C.S.I.C., Instituto "Miguel de Cervantes", 1984. El mismo resultado ofrece la consulta de: V. CAMPO, V. INFANTES, M. RUBIO, Catálogo de los pliegos sueltos poéticos del siglo XVII de la biblioteca de Antonio Rodríguez Moñino. Servicio de Publicaciones de la Universidad de Alcalá, Colección Repertorios Bibliográficos 1, 1995.

${ }^{20}$ Ver las obras de ESCUDERO, A. DOMÍNGUEZ GUZMÁN, La imprenta en Sevilla en el siglo XVII. Catálogo y análisis de su producción. 1601-1650. Sevilla, Secretariado de Publicaciones de la Universidad de Sevilla, 1992 y el Catálogo Colectivo del Patrimonio Bibliográfico Español entre otros.

${ }^{21}$ V. INFANTES, “¿Qué es una relación? (Divagaciones varias sobre una sola divagación)”, Las relaciones de sucesos en españa (1500-1750). Actas del primer Coloquio Internacional. Servicio de Publicaciones de la Universidad de Alcalá, 1996, pp. 203-216. Agradezco a la Dra. Carmen Espejo Cala el haberme facilitado este texto así como otras acertadas observaciones.
} 


\title{
5. TRANSCRIPCIÓN DE LA "EXHORTACIÓN"
}

\section{A MAYOR GLORIA DE DIOS}

\author{
EX OXRTACION \\ A LA PIEDAD, Y MAGNIFICENCIA \\ SEVILLANA, POR LA NECESSIDAD DE LA OBRA
}

de la Insigne Iglesia Colegial de nuestro Señor San Salvador, de la Muy Noble, y muy Leal Ciudad de Sevilla.

ESCRIVIALA

DEDICANDOLA AL QUE LEYERE.

D. ALONSO MARTIN BRAONES.

JESUS, MARIA, Y JOSEPH.

Atiendeme, devoto Sevillano,

oyeme, generoso limosnero:

Tú, que en cultos de Dios con franca mano

empleas tanta copia de dinero;

mover intento tu fervor Christiano,

tu liveralidad exitar quiero;

preste tu zelo oìdos à mis vozes,

que à tu heroyca piedad buelan velozes.

Tu, que del alto, Augusto Sacramento

eres amante, $y$ dàs de Fè pregones;

tu, que porque su Culto estè en aumento

te desposees de los ricos dones;

lee estas breves clausulas atento,

no atendiendo al que escribe estos renglones;

pues no soy yo el que hablarte solicito,

que es Dios el que te habla en este escrito.

Veinte, y tres años ha que derribado

de Nuestro Salvador el Templo vemos;

y de ver al Señor à el trasladado

dilatada esperanza mantenemos;

entretanto el Autor de lo criado

en indecente sitio lo atendemos;

y dà el mirarle alli penas mortales,

quando ay piedad, afectos, y caudales.

Entra en la Colegial, y tu desvelo verà del Sacramento la grandeza

en sitio que te cause desconsuelo viendo su cortedad, y su pobreza; entra, y veràs al Alto rey del Cielo, que quiere de tu amor ver la fineza; dale algo de lo mucho que te ha dado, 
porque esté en Ara honrosa colocado.

No seas como aquellos que avarientos, aunque à vista del Templo el passar vsan, no solo no fomentan sus aumentos con limosnas, que timidos rehusan, mas causando à los Cielos sentimientos por alli passan, y de dar se escusan algo à Dios de lo mucho que les sobra, y ni aun buelven los ojos à la obra.

En el Tabor Jesús transfigurado su cuerpo viò de resplandor vestido, de cuya gloria Pedro enamorado tres Templos fabricar ha pretendido; mas no fuera por necio señalado, si à Elias, y à Moyses diera al olvido, y para que el Christiano le adorasse solo à San salvador Templo labrase

Sombra fue de Jesús Sacramentado del testamento el Arca misteriosa, à quien erigiò Templo sublimado de Salomon la Majestad gloriosa; no assi en la Colegial Dios humanado en Templo habita, si en humilde choza; y en tanto tiempo por faltar tus dones està el Arca de Dios en pabellones.

Si vieras à Jesús recien nacido en el humilde pobre portalejo por darle sitio, à su Deidad debido, el ser pobre eligiera tu consejo; bien de tu voluntad tengo entendido le labrara vn Alcazar tu cortejo, que tu hazienda gastaras creer entablo, por quitar à Jesús del pobre establo.

Desabrigado en el portal medito oy en la Colegial à Dios humano, que le labres Alcazar solicito, tu generosidad abra la mano; si algo no dàs al que te diò infinito, donde està lo piadoso, y Sevillano? a ilustre Templo su grandeza passa, quitalo del portal, y dale casa.

Entra en tu casa, y mira sin zozobra tus alhajas, y de ellas has memoria, y muchas hallaràs que estàn de sobra, y solo sirven a la vana gloria; O si las dedicaras a esta obra, 
como te hizieras digno de la historia. O como si a otros dieras este ejemplo presto de Dios se levantara el Templo!

Quanto tienes, de Dios lo has recebido, quanto posees, te lo diò su mano; no que te quedes pobre he pretendido, si que le retribuyas cortesano; fabricale Palacio esclarecido al Alto, al Grande, al Rico, al Soberano; pues por mucho que a Dios le dès te arguyo, lue a Dios, que le daràs que no sea suyo!

Si poco puedes, porque pobre eres, y cortos medios tu caudal percibe; ofrece al Templo aquello que pudieres, pues Dios benigno todo lo recibe; y pues de Dios el premio es bien esperes en la gloria que eterna te apercibe, dale tu corta ofrenda al que sin duda tanto apreciò la de la pobre Viuda.

LAUS DEO, ET LAVS MARIAE.

La limosna recibe el Canonigo D. Joseph Fernando de Leon, Diputado de la obra.

Su Ilustrísima concede 40 dias de Indulgencia al que diere Limosna para esta obra.

\section{APÉNDICE}

Recopilando noticias de unos y otros autores, comenzando por la relación que ofrece el propio autor al final del Epítome de las Glorias de María, se puede elaborar la amplia y curiosa lista de títulos que se ofrece a continuación. Como complemento, se incluyen tras el título los siguientes datos: lugar de impresión, impresor, fecha, $\mathrm{n}^{\circ}$ de hojas ${ }^{22}$, autor que la cita (siempre que no sea simplemente copia de otros autores) y biblioteca donde actualmente se ha localizado un ejemplar. Se ha respetado en cursiva lo puesto así por Alonso Martín Braones, cuyo texto se reproduce entrecomillado. El tamaño de todas estas obras, según las describen todos los autores, es en $4^{\circ}$ :

1) "El presente libro de las Glorias de María, dedicado a la Santísima Trinidad" . Sevilla, Juan Antonio Tarazona, 1689 (84 h.). Escudero, n 1855, cita dos ejemplares, uno en la Biblioteca Nacional (B.N.) y otro en la Biblioteca de la Universidad de Sevilla

\footnotetext{
${ }^{22}$ Sin entrar a analizar las diferencias que sobre este dato pueden existir entre los autores, ni en las distintas formas en que pueden aparecer los títulos. La referencia de ejemplares actuales en diferentes bibliotecas españolas procede en su mayoría del Catálogo Colectivo de Patrimonio Bibliográfico. En conjunto, entiéndase esta relación como lo que es, un "Apéndice" al objeto principal del artículo, es decir, una simple aproximación a lo que debe constituir un catálogo completo de las obras de A. Martín Braones.
} 
(B.U.S.), donde aún hoy día se conservan. Hay además otro ejemplar en la Biblioteca Capitular Colombina (B.C.C.). Palau, no 34500, añade que "Ticknor cuenta 82 fols. Existe en la Biblioteca Nacional de Madrid".

2) "Triunfos de Jesús, dedicado a la Santísima Trinidad". Sevilla, Lucas Martín Hermosilla, 1686 ( 88 h.). Escudero, $n^{\circ} 1840$, cita dos ejemplares como en la obra anterior, uno en la B.N. y otro en la B.U.S., donde siguen estando, aunque son 2 los títulos conservados en la B.N., más otro ejemplar en la Biblioteca de la Universidad de Zaragoza. De él dice Palau, no 34499, que "Figuró este raro poema en la Biblioteca Ticknor, y existe en la Biblioteca Nacional de Madrid"

3) "La Relación lírica de la Fiesta del Sagrario de Sevilla, en acción de gracias por la victoria de Viena, dedicada al Ilustrísimo Cabildo de la Catedral de Sevilla". Sevilla, Juan Francisco de Blas, 1683 (24 h.) Gallardo, $\mathrm{n}^{\circ}$ 1472, lo describe sin citar procedencia; Escudero, $\mathrm{n}^{\circ} 1821$, dice que hay "un ejemplar en la colección de Varios de la Biblioteca Universitaria de Sevilla" no localizado ${ }^{23}$. Lo mismo recoge Palau, $n^{\circ} 34496$. Simón Díaz (1972), n 1311, cita una copia en la B.N. Hay actualmente ejemplares en la B.N., la Real Academia de la Historia (R.A.H.) y un tercero, que Matute ya recoge, en la B.C.C.

4) "Las Aspiraciones Jaculatorias para los siete días de la semana, dedicadas al Santísimo Sacramento del Altar". Están encuadernadas al final de los Triunfos de Jesús.

5) "La Canción Real a la Santa Iglesia de Sevilla, dedicada al Coro de la misma Santa Iglesia”. Sevilla, por Lucas Martín de Hermosilla, 1686 (4 h.). Palau n 34498 lo describe sin citar ejemplar, lo que sí hace J. Simón (1972), procedente del Archivo Municipal de Sevilla, Conde del Aguila, t.5 en $4^{\circ}$ (26). Ejemplares también en la B.N. y en la R.A.H.

6) "Las Breves Memorias de los Santos Patronos de Sevilla, dedicadas a los mismos Santos Patronos".. Según Palau, n 34501, impreso en Sevilla hacia 1690, 4 h.

7) "Las Letras de los Villancicos que cantaron los Niños Seises de la Santa Iglesia de Sevilla en los Maitines de la Resurrección del Señor el año 1683".

8) "El Cántico Nuevo a la Concepción de Nuestra Señora, que empieza: Todo el Coro Celestial dedicado al Gloriosísimo Patriarca el Señor San Ioseph”.

9) "El Elogio latino a la Concepción de Nuestra Señora, glosando en espinelas castellanas la redondilla que empieza: Omnis Chorus celestialis, dedicado a la Virgen María Nuestra Señora."

10) "Los Siete Sonetos a Nuestra Señora, a San Miguel, S. Gabriel, San Rafael, al Angel Custodio y a San Florencio Mártir Hispalense, dedicados a los Niños Seises de la Santa Iglesia de Sevilla".

11) "Un papel en 150 redondillas intitulado, Respóndese a una pregunta de una criatura, dándole breves reglas de Oración, que empieza diziendo Hijo lei tu papel, dedicado al Lector". (4 h.) J. Simón (1972) no 306 cita ejemplar en la B.N. que no he localizado.

\footnotetext{
${ }^{23}$ Aunque es posible que salga de nuevo a la luz, así como el título $\mathrm{n}^{\circ} 17$, tras la catalogación que en estos momentos se lleva a cabo de los tomos de Varios. Esta información más la confirmación de las obras de Braones actualmente localizables en la B.U.S. los debo a la siempre amable colaboración de D. Eduardo Peñalver Gómez, Jefe de la Sección de Fondo Antiguo y Archivo Histórico de la Universidad de Sevilla
} 
12) "Otro papel en 150 coplas de Romance, intitulado: Compónese un ramillete de virtudes para una criatura recién entrada en Religión, que empieza diciendo: Gracias a Dios Hijo mío, dedicado a la Reyna de los Ángeles Maria Nuestra Señora".

Y concluye así Braones esta relación: "Y aunque estos tres últimos se imprimieron sin mi nombre, al presente los declaro por míos, porque en ningún tiempo se le atribuyan a nadie mis defectos".

A esta lista hay que añadir los siguientes cuatro títulos ya citados por A. de la Cuesta y otros recogidos por diversos autores:

13) Mojiganga de D Inés de Castro titulada "Beber, morir y vivir"

14) La fiesta de Ynocentes para festejo de carnestolendas el año de 1665

15) Loa para la Comedia de Afectos de Odio y Amor en Cuelga de una Religiosa de Santa Inés de Sevilla hija del Duque de Alcalá año de 1671

16) Loa de los quatro elementos para fiesta de Nuestra Señora de Aguas Santas año de 1666

17) Función de desagravio a la Virgen María en 1691, Sevilla, Juan Francisco de Blas, 1691 (4 h.). Escudero, n 1879, cita un ejemplar en la "Colección de Varios de la Biblioteca de Sevilla", no localizado actualmente. También Palau no 34502 alude a este ejemplar como de la "Biblioteca Provincial de Sevilla".

18) Noticia de las fiestas que se han hecho en la ciudad de Sevilla, en honor de una imagen de N. Señora, que ofendida (ya fuese de acaso, o ya de malicia), fue festejada con célebres devotos cultos en la iglesia parroquial de Santa María Magdalena, Sevilla, Juan Francisco de Blas, 1691 (Matute, p. 4, de todos los títulos que recoge sólo de éste dice: "Yo he visto la siguiente (obra)" y aporta la fecha, lo que no hace Escudero, $\mathrm{n}^{\circ} 1972$, quien tampoco cita ejemplares, ni Palau n 34494 ("Hacia 1680"). Hoy se conserva uno en la B.N.

19) Los Órganos, (entremés de 1669 según Méndez Bejarano).

20) Copia de un papel... en que se da segunda noticia del grande aumento a que ha llegado en la ... ciudad de Sevilla la devoción al santísimo Rosario de la Virgen María, Valencia, Imprenta de Iayme de Bordazar, 1691. J. Simón (1983) n 5284 recoge un ejemplar en el British Museum. Localizados hoy una copia en la British Library y a través del Catálogo Colectivo de Patrimonio Bibliográfico Español otros 3 ejemplares: en el Instituto de bachillerato Luis Vives de Valencia, Biblioteca Histórica de la Universidad de Valencia y Biblioteca Valenciana.

21) Noticia quinta del estado, y progresso, que tiene dentro, y fuera de la Muy Noble, y muy leal ciudad de Sevilla la devoción del Santísimo Rosario de la siempre Virgen María, S.1. : s.n., s.a. (4 h.). J. Simón Díaz (1972 y 1983), nº 304 y 5287 respectivamente. Cita ejemplar en la B.N. que se conserva.

22) Guirnalda de doze Rosas, y un lirio que pone en la Sagrada Cabeza de la Soberana Virgen María... a quien la dedica y consagra en esta Sexta Noticia del Estado..., Sevilla, Juan Francisco de Blas, 1695. (2 h.) J. Simón (1972) no da fecha y cita ejemplar en la B.N., donde hoy se conservan 2 copias.

23) Afectos de contrición que ofrece al altísimo Jesús..., 4 h. S.1., s.a. Ejemplar en la B.N. 
24) Llegamos así al título vigesimo cuarto si incluimos, cómo no, la Exortación a la piedad y magnificencia sevillana... Gallardo $\mathrm{n}^{\circ} 1473$ no indica fecha alguna. Tampoco Simón Díaz (1983) n ${ }^{\circ} 5286$, que copia al anterior. Sin embargo, este autor en su Bibliografía de la Literartura Hispánica, VI, n 6613 describe el ejemplar citando el actual de la B.N. Para Escudero, n 1973, "corresponde esta impresión al último tercio del siglo XVII'. Palau, $\mathrm{n}^{\circ}$ 34495, afina más aunque no se aproxima mucho: "hacia 1680 "... ${ }^{24}$

Pero aquí no puede concluir definitivamente la lista por dos claros motivos: el primero nos lo decían ya Góngora: "A escrito mucha copia de diferentes poemas a varios asumptos pero los que a sacado a luz asta este año de 1687" y Cuesta: "Escrivió varios epigramas latinos, y variedad de versos castellanos en distintos metros con sa[]onados picantes, que de mano andan entre los curiosos". Es decir, muchas obritas quedaron inéditas. Si además no las firmaba, hoy día aunque se conserven está inevitablemente perdida su atribución. Sólo nos ha quedado la descripción de una de ellas dada por José Cevallos: "un papel manuscrito sobre los abusos de los Rosarios en Sevilla, y sobre que no se devían hacer estaciones con ellos, sino en tiempo de necesidad. Es como un sermón".

En segundo lugar, no olvidemos tampoco lo que decía Ambrosio de la Cuesta tras citar algunos de sus títulos: "y otros muchos que despreciados de su humildad, y desengaño entregó a el fuego". Es posible que Braones lo hiciera por el motivo con que encabezaba todas sus obras, "A Mayor Gloria de Dios". De ser así no cabe duda que lo mismo opinarán, aunque por muy diverso motivo, sus actuales críticos.

\footnotetext{
${ }^{24}$ Puede consultarse el registro completo de esta obra en: M.C. GARCÍA DE ENTERRÍA y J. MARTÍN ABAD (dirs.), Catálogo de pliegos sueltos poéticos de la Biblioteca Nacional. Siglo XVII, Madrid, Ministerio de Educación y Cultura, 1998, n 198 y en su catálogo general a través de Internet: $<$ http://www.bne.es $>$.
} 